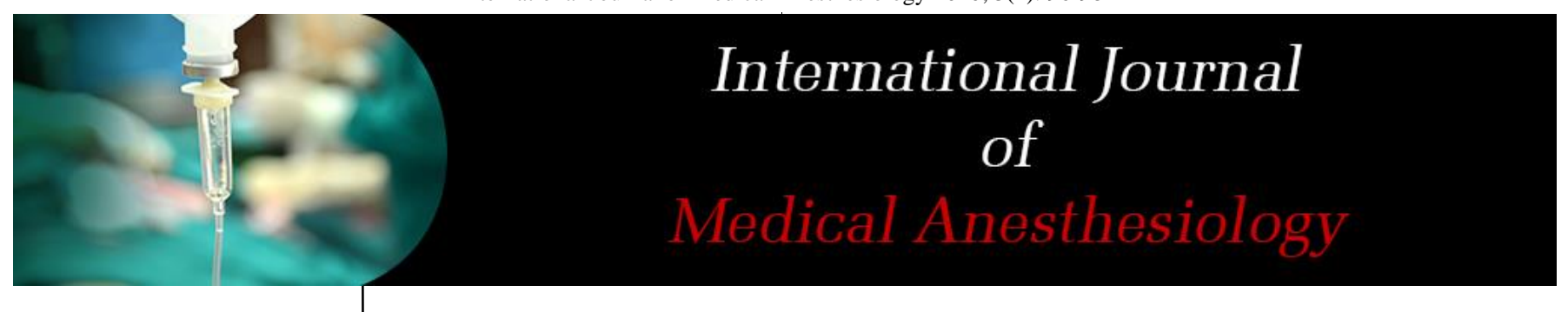

E-ISSN: 2664-3774

P-ISSN: 2664-3766 Www.anesthesiologypaper.com IJMA 2020; 3(1): 96-98

Received: 10-11-2019

Accepted: 14-12-2019

Dr. Jitesh Marian Rasquinha Associate Professor, Department of Anesthesiology, Kanachur Institute of medical Sciences, Deralakatte, Mangalore, Karnataka, India
Corresponding Author: Dr. Jitesh Marian Rasquinha Associate Professor, Department of Anesthesiology, Kanachur Institute of medical Sciences, Deralakatte,

Mangalore, Karnataka, India

\section{A study of pain score: A comparative pain score evaluation of lumbar epidural block using $0.5 \%$ bupivacaine and $0.5 \%$ bupivacaine with ketamine}

\author{
Dr. Jitesh Marian Rasquinha
}

DOI: https://doi.org/10.33545/26643766.2020.v3.i1b.74

\begin{abstract}
Intrathecal and epidural administration of opioids are widely used even now. Opioid administration intrathecally or epidurally causes dependable method of pain relief without affecting motor functions or other sensory modalities such as touch sensation. This study is an effort to find the efficacy of lumbar epidural block using $0.5 \%$ bupivacaine vs $0.5 \%$ bupivacaine with ketamine.
\end{abstract}

Keywords: Epidural, bupivacaine, ketamine, pain score

\section{Introduction}

Epidural block using local anaesthetic drugs are used in clinical practice since many years ${ }^{[1-}$ 3]. It further got revolutionized with the better understanding of opioid receptors by Martin \& Coworkers in1976. Intra spinal morphine was first used in 1979, which opened up a new exciting way of pain management ${ }^{[4,5]}$.

Mankowitz E et al. (1982) ${ }^{[6]}$ first used epidural ketamine. Ketamine hydrochloride $4 \mathrm{mg}$ in $10 \mathrm{ml}$ of $5 \%$ dextrose water was administered epidurally to 7 patients suffering from intractable pain in the back, lower abdomen and legs. Pain relief was obtained in all cases. Duration of action varied from half an hour to more than six hours. Naguib M et al. (1986) ${ }^{[7]}$ studied thirty-four patients ASA physical status I or II scheduled for gall bladder surgery in a comparative prospective trial to evaluate the efficacy of epidural and intramuscular ketamine for post-operative pain relief. They were divided randomly into three groups. Group I (11 patients) received $30 \mathrm{mg}$ intra muscular ketamine. Group II (10 patients), Group III (13 patients) received 10 and $30 \mathrm{mg}$ ketamine in $10 \mathrm{ml}$ Saline respectively through epidural catheters. Pain was evaluated every two hours for first 24 hours post operatively by using linear analogue pain scale from $0-10$. Ketamine was given on patients' request and whenever pain score exceeded three. Ketamine produced analgesia in all the patients studied. Reduction of pain score after two and four hours in Group I and III was significant when compared to Group II. Seven patients (54 percent) in Group III did not require further analgesia after the initial injection. However, following $10 \mathrm{mg}$ epidural ketamine or $30 \mathrm{mg}$ IM ketamine, post-operative pain was more frequent. Four patients who received epidural ketamine complained of transient burning pain in the back during injection. This study is an effort to find the efficacy of lumbar epidural block using $0.5 \%$ bupivacaine vs $0.5 \%$ bupivacaine with ketamine.

\section{Aims and Objectives}

This study is an effort to find the efficacy of lumbar epidural block using $0.5 \%$ bupivacaine vs $0.5 \%$ bupivacaine with ketamine.

\section{Materials and Methods}

A prospective randomized double-blind study was conducted in 60 patients admitted at for various elective surgical procedures during the period 2018 -2009. Surgical procedures which required blockade below T6 dermatome was only selected.

\section{Inclusion criteria}

- ASA physical status - I- patients

- Both male and female 
- 20 -40 years age groups

- Weight $40-90 \mathrm{kgs}$

\section{Exclusion criteria}

- Difficult airway

- Previous history of anaesthetic complications

- History of local anaesthetic allergy

- Spinal deformities

- Preexisting neurological deficits

- Cases with contra indication to regional anaesthesia

Total sample sizes of 60 patients were randomly allocated into two groups. Control groups-Group-I-received $0.5 \%$ bupivacaine, $1.5 \mathrm{ml}$. spinal segment to be blocked $(\mathrm{n}=30)$ : (Not exceeding $2 \mathrm{mg} / \mathrm{kg}$ body weight) and Group-II $(\mathrm{n}=30)$ received bupivacaine $0.5 \% \quad 1.5 \mathrm{ml}$.spinal segment to be blocked plus preservative free $1 \%$ ketamine in a dose of 0.5mg.kg body weight.

On the previous day of surgery, a detailed pre anaesthetic evaluation were done in all cases. Procedure was explained and written informed consent were obtained from the patients and relatives. All patients were kept nil per oral from 10.00 P.M on the previous day of surgery and premedicated with tablet. Diazepam $0.2 \mathrm{mg} . \mathrm{kg}$ body weight.

\section{Procedure}

On the day of surgery, in the operating room 18-gauge intravenous cannula was placed in a peripheral vein in the non-dominant upper limb and patients were connected to monitors. Non-invasive blood pressure (NIBP). Pulse oximetry and continuous ECG were recorded on Philips monitor (Agilent 1204 A model). All patients received intravenous premeditation with Injection diazepam $0.2 \mathrm{mg} . \mathrm{kg}$ body weight mixed with $21.3 \mathrm{mg}$ of lignocaine $2 \%$ over 5 minutes. Base line blood pressure and heart rate were recorded. All parents were preloaded with intravenous fluidringer lactate $10 \mathrm{ml} . \mathrm{kg}$ body weight before performing epidural block.

All patients were put is left lateral position and under all aseptic precautions lumbar L3-L4 interspace was identified and infiltrated with $\mathrm{lml}$ of $2 \%$ Lignocaine. Epidural space were identified by introducing a 18 gauge Tuohy needle using loss of resistance technique. Group-I-patients $(n=30)$ received bupivacaine $0.5 \% \quad 1.5 \mathrm{ml}$. spinal segment to be blocked and Group-II-Patients $(n=30)$ received bupivacaine $0.5 \% 1.5 \mathrm{ml}$. spinal segment to be blocked plus preservative free ketamine $1 \%, 0.5 \mathrm{mg} . \mathrm{kg}$ body weight as single shot epidurals. Patients were made to lie down supine and an independent fellow resident recorded the following study parameters. Post-operative pain score by modified visual analogue scale (VAS)

\section{Results}

Table 1: Shows the distribution of patients according to pain score.

\begin{tabular}{|c|c|c|c|c|}
\hline \multirow{2}{*}{$\begin{array}{l}\text { Score } \\
\text { Scale }\end{array}$} & \multicolumn{4}{|c|}{ Number of patients } \\
\hline & Group I & $\%$ & Group II & $\%$ \\
\hline 0 & 0 & 0.0 & 0 & 0.0 \\
\hline 1 & 0 & 0.0 & 1 & 3.3 \\
\hline 2 & 1 & 3.3 & 5 & 16.7 \\
\hline 3 & 2 & 6.7 & 20 & 66.7 \\
\hline 4 & 1 & 3.3 & 2 & 6.7 \\
\hline 5 & 5 & 16.7 & 0 & 0.0 \\
\hline 6 & 9 & 30.0 & 2 & 6.7 \\
\hline 7 & 8 & 26.7 & 0 & 0.0 \\
\hline 8 & 4 & 13.3 & 0 & 0.0 \\
\hline 9 & 0 & 0.0 & 0 & 0.0 \\
\hline 10 & 0 & 0.0 & 0 & 0.0 \\
\hline Total & 30 & 100.0 & 30 & 100.0 \\
\hline
\end{tabular}

\section{Discussion}

About $90 \%$ of the patients in Group I has a pain score of $>=$ 4 compared to $13.4 \%$ in Group II corresponding to the same score. The means $( \pm \mathrm{SD})$ pain score for Group II $(3.03 \pm$ 1.0) was significantly less than Group I (5.97 \pm 1.52$)$ (Table 10, $p<0.05$, based on Mann Whitney - u-test for independent samples) Mean pain score for Group II (3.03 \pm 1.0) was significantly less than Group I $(5.97 \pm 1.52)$ based on Mann-Whitney U test for independent samples at $P<0.05$ Intrathecal and epidural administration of opioids are widely used even now. Opioid administration intrathecally or epidurally causes dependable method of pain relief without affecting motor functions or other sensory modalities such as touch sensation. Epidural block using local anaesthetic drugs are used in clinical practice since many years. It further got revolutionized with the better understanding of opioid receptors by Martin \& Coworkers in1976. Intra spinal morphine was first used in 1979, which opened up a new exciting way of pain management.

\section{Conclusion}

Mean pain score for Group II (3.03 \pm 1.0$)$ was significantly less than Group I $(5.97 \pm 1.52)$ based on Mann-Whitney U test for independent samples at $P<0.05$

\section{References}

1. Kawana Y, Sato H, Shimada H, Fujita N, Veda Y, Hayashi A et al. Epidural ketamine for postoperative pain relief after gynaecologic operations: a double-blind study and comparisons with epidural morphine: Anesth Analg 1987; 66(8):735-738.

2. Peat SJ, Bras P, Hanna MH. A double-blind comparison of epidural ketamine and diamorphine for postoperative analgesia: Anaesthesia. 1989; 44(7):555558.

3. Naguib M, Sharif AM, Seraj M, Gammal M, Dawlathy AA. Ketamine caudal analgesia in children: comparison with caudal bupivacaine, Br. J Anaesth. 1991; 67(5):559-64. 
4. Nagasaka H, Nagasaka I, Sato I, Matsumoto N, Matsumoto I, Hori T. The effects of ketamine on the excitation and inhibition of dorsal horn WDR neuronal activity induced by bradykinin injection into temporal artery in cats after spinal cord transection. Anesthesiology 1993; 78(4):722-32.

5. Gebhardt B. Pharmacology and clinical results with peridural and clinical results with peridural and intrathecal ketamine. Anaesthetist. 1994; 43:S34-40.

6. Mankowitz E, Brock-Utne JG, Consnett JE, GreenThompson R. Epidural ketamine a preliminary report. S. Afr. Med J. 1982; 61(12):441-2

7. Naguib M, Adu-Gyamfi Y, Absood GH, Farag H, Gyasi HK. Epidural ketamine for post-operative analgesia. Can Anaesth Soc J. 1986; 33(1):16-21. 